\title{
Herpes simplex esophagitis
}

\author{
Sameer Bahkali, ${ }^{1}$ Hajer Al-Zahrani, ${ }^{2}$ Rana Al-Zahrani, ${ }^{2}$ Sara Al-Qahtani ${ }^{2}$ \\ ${ }^{1}$ National Guard Health Affairs; ${ }^{2}$ King Saud bin Abdul-Aziz University for Health Sciences, Riyadh, Kingdom of Saudi Arabia
}

\begin{abstract}
One of the well-known complications of immunosuppression is herpes simplex esophagitis and it is rarely found in immunocompetent patients. We present a case of a 75-year-old female known case of diabetes mellitus, hypertension and dyslipidemia with two-month history of dysphagia and odynophagia to solid mainly and cough tinged with blood. On esophagogastroduodenoscopy there was right side of oropharynx ulcer, edema and focal erythema with compression on the esophageal entrance. Biopsy confirmed esophagitis and findings characteristic of herpes simplex virus infection. After the diagnosis was made, the patient was treated with prednisone for 10 days and famciclovir for 14 days and showed significant improvement in a period of nearly 2 weeks. We recommend antiviral treatment even for immunocompetent patients for the clear acceleration of the recovery time and prevention of possible complications.
\end{abstract}

\section{Imaging in Internal Medicine}

This is a 75-year-old Saudi female, presenting with a history of 2-month dysphagia and odynophagia to solid mainly and cough tinged with blood. No history of vomiting, fever, change of voice. No history of pneumonia, recurrent infections or bronchial asthma. Also, no history of neck masses, weight loss or night sweats. No ear pain or dental infection. There was no history of recent antibiotic or corticosteroid use. She is a known case of diabetes mellitus, hypertension and dyslipidemia on medications. Patient is married, unemployed and nonsmoker. No previous similar complaint or significant family history.

Normal general physical examination except for small white patches at right side of the oropharynx with no ulceration or bleeding. No lymphadenopathy.

Correspondence: Sara Al-Qahtani, King Saud bin Abdul-Aziz University for Health Sciences, Al Hars Al Watani, Ar Rimayah, Riyadh 14611, Kingdom of Saudi Arabia.

E-mail: s.alqahtani90@hotmail.com

Key words: Herpes simplex esophagitis; herpes simplex virus infection.

Conflict of interest: the authors declare no potential conflict of interest.

Received for publication: 9 June 2017.

Accepted for publication: 5 July 2017.

This work is licensed under a Creative Commons Attribution NonCommercial 4.0 License (CC BY-NC 4.0).

CCopyright S. Bahkali et al., 2017

Licensee PAGEPress, Italy

Italian Journal of Medicine 2017; 11:413-414

doi:10.4081/itjm.2017.894
Upper gastrointestinal series showed upper esophageal web and esophageal tertiary contractions (Figure 1).

Neck computed tomography was done and showed fullness of left pyriform sinus and esophageal diverticulum (Figure 2).

Histopathology from the esophageal biopsy specimens revealed histologic features consistent with a focal ulceration with herpes viral infection. The HSV2 immunostaining was positive for rare viral inclusions, consistent with herpes viral infection ulcerative process. After the diagnosis was made, the patient started treatment with prednisone $30 \mathrm{mg}$ for 10 days and famciclovir $500 \mathrm{mg}$ for 14 days. The patient has dramatically improved over a period of nearly 2 weeks.

Esophagitis is mostly caused by non-infectious causes. Infectious esophagitis is most commonly caused by candid, herpes simplex virus (HSV) and cytomegalovirus. ${ }^{1,2} \mathrm{HSV}$ type 1 is the most common type and male to female ratio is $3: 1$; however, we are reporting a female case with HSV2. ${ }^{2}$

One of the well-known complications of immunosuppression is herpes simplex esophagitis (HSE) and it is rarely found in immunocompetent patients; which is, in this case, considered a self-limiting disease and rarely necrotic and diffuse. ${ }^{3,4}$

For patients with typical symptoms of esophagitis with no clear cause, specially if the ulcers involve distal or mild esophagus, HSE should be suspected and investigated even in immunocompetent patients regardless of the age or gender. Antiviral treatment is established for immunosuppressed patients and need more evidence for immunocompetent patients. We recommend antiviral treatment even for immunocompetent patients for the clear acceleration of the recovery time and prevention of possible complications. 


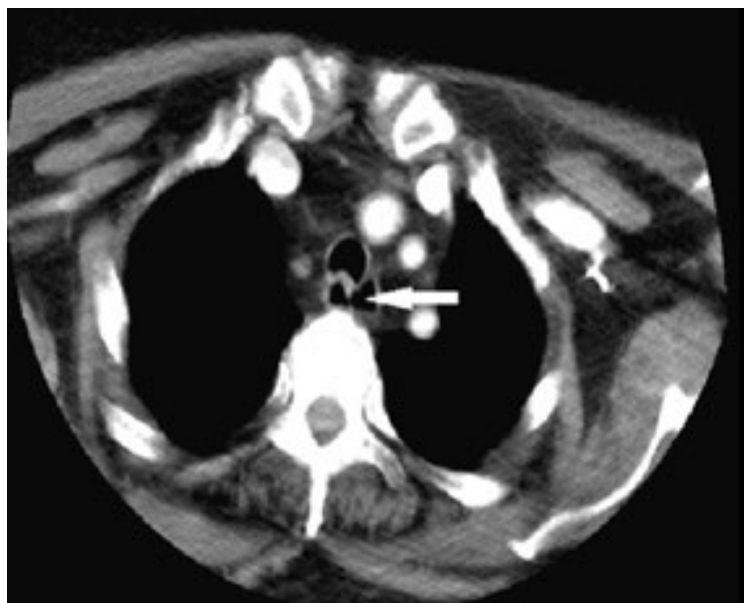

Figure 2. An air pocket seen arising from the esophagus consisting with esophageal diverticulum without clear Figure 1. Esophageal tertiary contractions.

\section{References}

1. Geraci G, Pisello F, Modica G, et al. Herpes simplex esophagitis in immunocompetent host: a case report. Diagn Ther Endoscop 2009 ;2009:717183.

2. Sathyanarayanan V, Razak A, Prabhu MM, et al. A case report of herpetic and candidal esophagitis in an im-

munocompetent adult. Asian Pacific J Trop Biomed 2011;1:251-2.

3. Desigan G, Schneider RP. Herpes simplex esophagitis in healthy adults. Southern Med J 1985;78:1135-7.

4. Généreau T, Rozenberg F, Bouchaud O, et al. Herpes esophagitis: a comprehensive review. Clin Microbiol Infect 1997;3:397-407. 